\title{
O fim da crítica?
}

\section{Nikolai Pesochinsky}

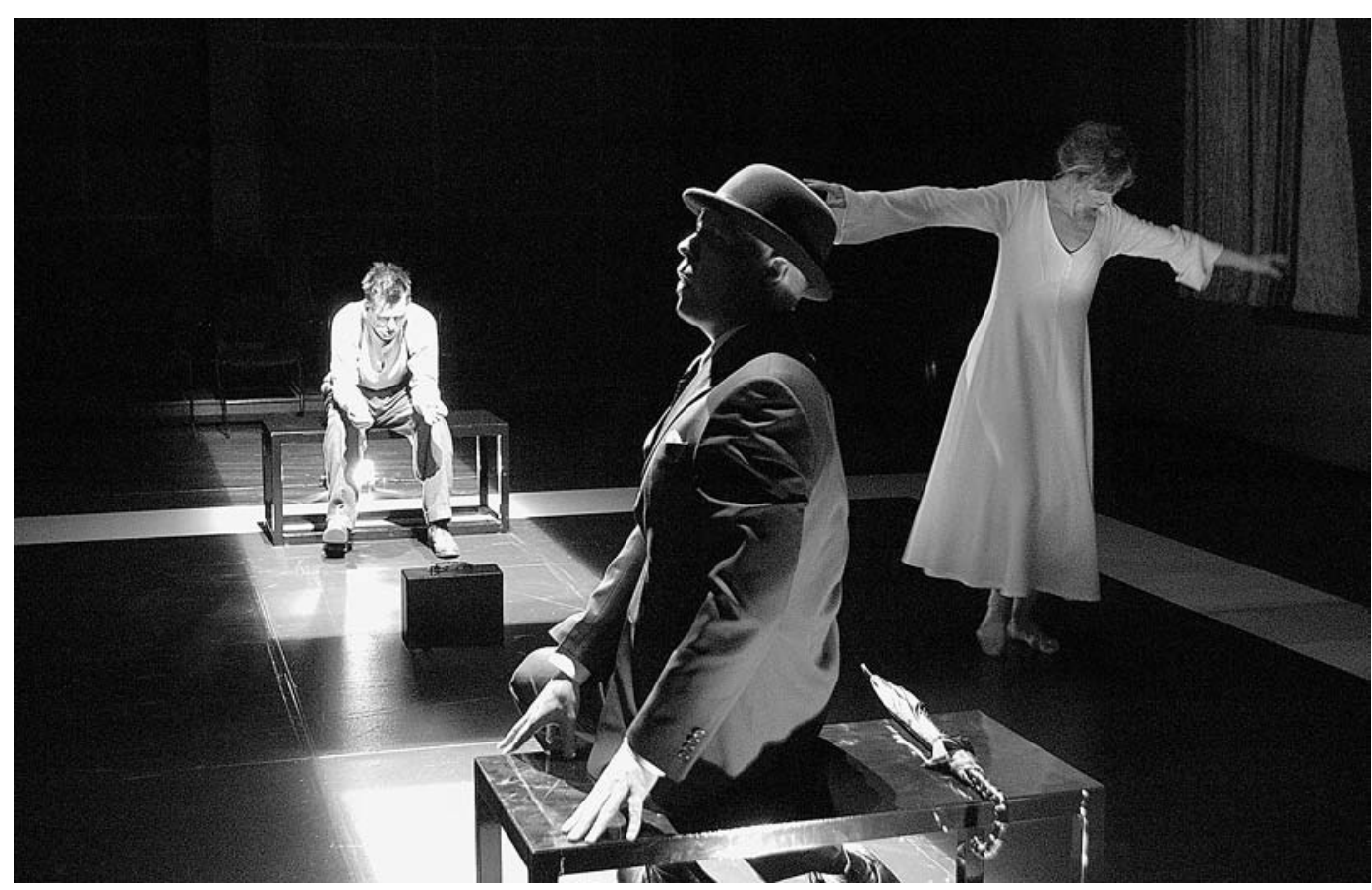

As minhas primeiras questões são óbvias: porque é que diversos críticos vêem no mesmo palco, ao mesmo tempo, espectáculos "diferentes"? Porque é que lemos a acção desta ou daquela maneira? 0 que é que vemos e de que é que não nos apercebemos? Trata-se de estar certo ou errado? Terá importância?

Como simples ilustração destas questões, poderia começar por discutir a diversidade de reacções críticas despertadas por um espectáculo da SITI Company ${ }^{1}$, de Nova lorque, Death and the Ploughman [Morte e o lavrador $]^{2}$. A leitura dos textos publicados por críticos como Mark Seamon, Chris Jones, Alexis Soloski, Leah B. Green, Jill Stevenson, Stephanie Bunbury, Allison Croggon, Matthew Murray, Matthew Richter, Les Gutman, Bred Fetzer ou Charles Isherwood, revela não só opiniões muito diversas sobre o desenho de movimento - uma dimensão muito importante do espectáculo porque era responsável pela criação da essência da forma visual daquela proposta, baseada num diálogo filosófico medieval -, mas também divergências acentuadas sobre outros aspectos básicos da "representação", tais como o padrão dramático da acção, a partitura emotiva e a medida do impacto filosófico e estético no público através de mecanismos teatrais. 0 principal problema da análise daquela criação parece, aliás, mergulhado nalguma confusão: trata-se da questão metodológica da relação (ou justaposição) da partitura de movimentos com as outras dimensões da acção. 0 que torna dificil a consideração da estrutura integral do acontecimento dramático produzido com o recurso a uma vasta gama de recursos. Tão diversas eram também as descrições do estilo e da forma dramáticas, bem como as respostas emocionais ao espectáculo - desde a "possessão por um deus" ao adormecimento do público, de "poderoso", "fantasticamente dramático" e "vibrante" a "frio" -, que se torna interessante imaginar que memória, dentro de uns dez anos, poderá o investigador de teatro, com base nestas recensões críticas, recuperar deste espectáculo de Anne Bogart... ${ }^{3}$

É claro que qualquer exercício de crítica artística bem como a percepção de qualquer objecto artístico parte de uma percepção pessoal e sensual. A que depois se acrescentam diferentes convicções sociais e filosóficas, diferentes experiências dos espectadores e diferentes valores pessoais. Cada um de nós vai ao teatro com disposições muito distintas e pode acontecer-nos apreciar hoje uma coisa da qual não nos teríamos apercebido dois dias antes. A sociedade liberal, a mentalidade pós-moderna e as teorias da comunicação contemporâneas criaram uma base firme para a defesa do direito do crítico a ser completamente relativo, "parcial" e livre de expressar simplesmente uma opinião "pessoal".

Desde o período do teatro simbolista, e particularmente durante as vanguardas das primeiras décadas do século $X X$, mais tarde com a arte surrealista e finalmente com a
Death and the

Ploughman, de Johannes von Saaz, enc. Anne Bogart, SITI Company, Nova lorque, 2004.

1 A SITI Company foi fundada em 1992 por Anne Bogart e Tadashi Suzuki, como um projecto assumidamente empenhado na redefinição e revitalização do teatro contemporâneo nos Estados Unidos, através de uma ênfase nas colaborações e diálogos internacionais. (N. T.)

${ }^{2}$ Trata-se de uma encenação do famoso diálogo de Johannes von Saaz, datado de 1401 estreada em Abril de 2004 no Wexner Center in Columbus, Ohio, naquilo que constituiu uma revelação teatral deste texto nos Estados Unidos. Este texto foi levado à cena em Portugal como O lavrador da Boémia, pelo CENDREV, com encenação de Jean-Pierre Sarrazac, em 1997. (N. T.)

3 Na versão original deste texto, eram fornecidos amplos exemplos das diferenças e divergências sumariamente referidas, citando extensos passos das recensões dos críticos referidos. Por óbvias razões de espaço, e com o acordo generoso do autor, optámos por omitir tais exemplos. (N.T.) 


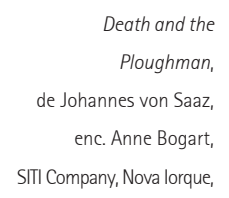

2004.

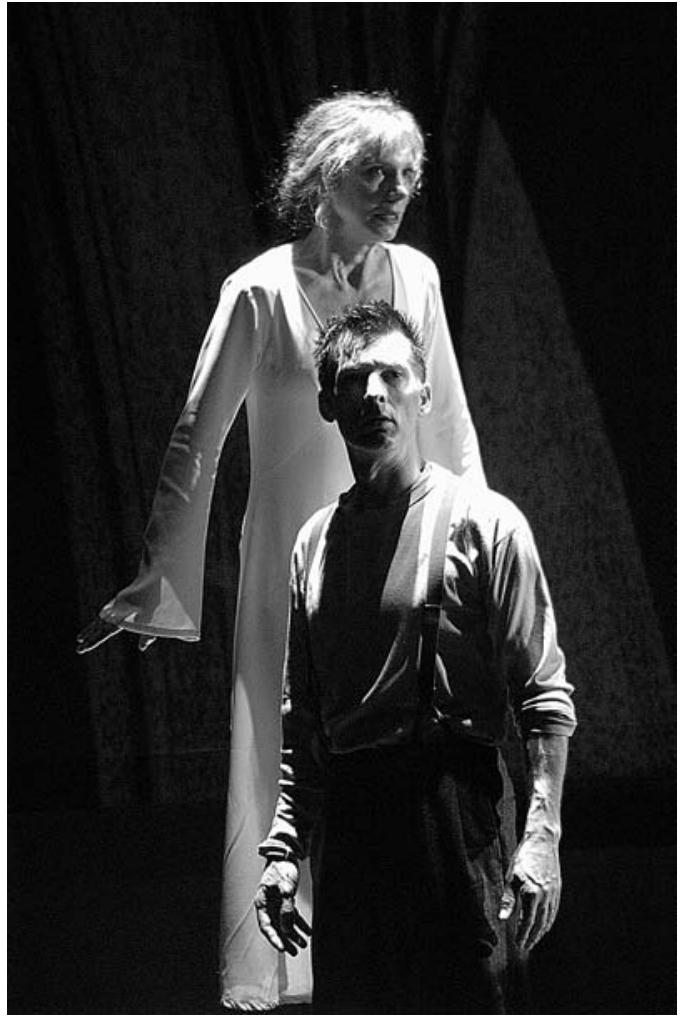

0 objecto é uma coisa, a sua interpretação outra, e a sua avaliação é ainda uma outra - aqui temos os três passos distintos do trabalho do crítico. Podemos ter diferentes interpretações e avaliações do objecto, mas se não formos capazes de "perceber" todo o objecto então temos um problema sério. 0 nosso objecto é o texto teatral, a acção teatral e a forma teatral. E nenhum texto nem nenhuma forma são completamente informes ou invisiveis.

Os movimentos do espectáculo de Anne Bogart são, em principio, ora expressivos da personalidade das personagens, ora abstractos. Poderão funcionar ainda como um paralelo, como uma espécie de contraponto textual, reflectindo o mesmo tema. Ou será que o movimento aliena o nivel pessoal da história, lançando a narração para uma dimensão cósmica? Ou será, ainda, que o movimento cria uma história paralela (uma segunda intriga): sobre a inevitabilidade da incompreensão das almas humanas como planetas. Será possível vermos nisto uma variante da Eurrítimica de Rudolph Steiner? Ou simplesmente uma decoração atraente de uma verborreia moralista? Mas não é possivel vermos tudo ao mesmo tempo. Uma coisa ou outra. Abstracto ou psicológico, pessoal ou impessoal, ilustrativo ou não-figurativo, emocional ou intencionalmente desapaixonado, ora os padrões de movimento das três pessoas estão relacionados entre si ou funcionam de forma completamente isolada uns dos outros. É uma questão da forma que efectivamente vemos no palco. Se a "virmos", então seremos capazes de a interpretar e de a ligar com outras ideias. Mas dez pessoas diferentes vêem dez formas diferentes, ou sugerem formas diferentes. É então que o fim da crítica parece próximo.

Eu acredito na capacidade de uma leitura profunda e precisa do texto teatral - este é provavelmente o nivel básico do nosso trabalho profissional, e distingue o nosso labor da fruição do espectador que se limita a ter uma sensação subconsciente daquilo que se passa no palco. coisas que escolhemos ver (mesmo quando essa escolha é subconsciente)? 


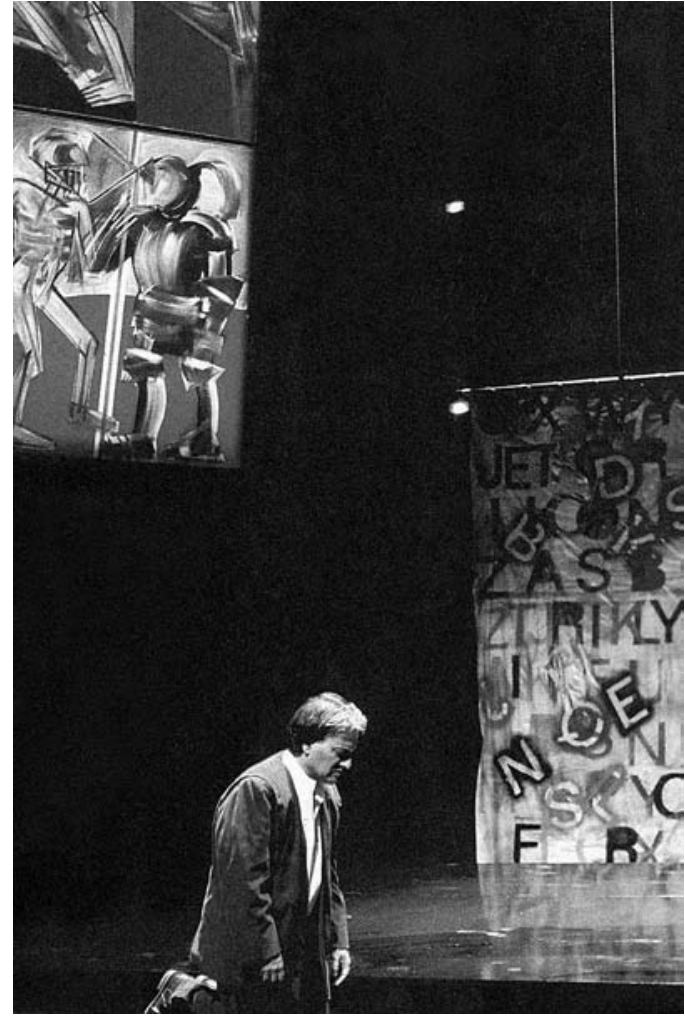

Não será a leitura da poética teatral, ou da forma teatral, a nossa capacidade básica? E esta poética ou forma teatral não é uma sombra, um sonho. Em certa medida, trata-se de um produto, embora um produto deliciosamente artesanal. E nós podemos dizer como é que funciona, porque está tudo expresso nos recursos da acção teatral. Trata-se da estrutura, da composição e do estilo da acção teatral. Estes parâmetros parecem ser particularmente abertos à descrição que pode ser motivada e explicada. Mas poderemos nós dizer que temos uma qualquer metodologia de análise de espectáculos?

$\mathrm{Na}$ realidade da nossa profissão, muitas vezes, uma crítica é simplesmente uma parte de uma representação suficiente do espectáculo. Mas não podemos esperar que o espectador leia cinco críticas contraditórias, as compare, se recorde dos valores que são habitualmente importantes para Alexis Solosky e outros críticos, compare o artigo de Charles Isherwood com os seus textos anteriores e depois decida que percepção deve funcionar para si enquanto espectador.

Precisará verdadeiramente o espectador das impressões livres de um conjunto de críticos "relativistas"? Será que isso ajuda mais do que uma nota de imprensa com informação básica sobre os princípios artísticos e os objectivos criativos da equipa e do encenador? Com que frequência é que nós vamos mais longe em termos metodológicos para além daquilo que surge representado na nota de imprensa, avançando para os pormenores da análise? Não acontece por vezes que nos limitamos a acrescentar a nossa avaliação à descrição de alguns aspectos básicos da peça e da representação?

0 nosso objectivo é a criação de uma opinião pública em torno de certos artefactos e de ideias artísticas. Representamos o acontecimento teatral de modo a descobrir algum prazer espiritual e estético para os espectadores, a explicar algumas ideias artísticas mais

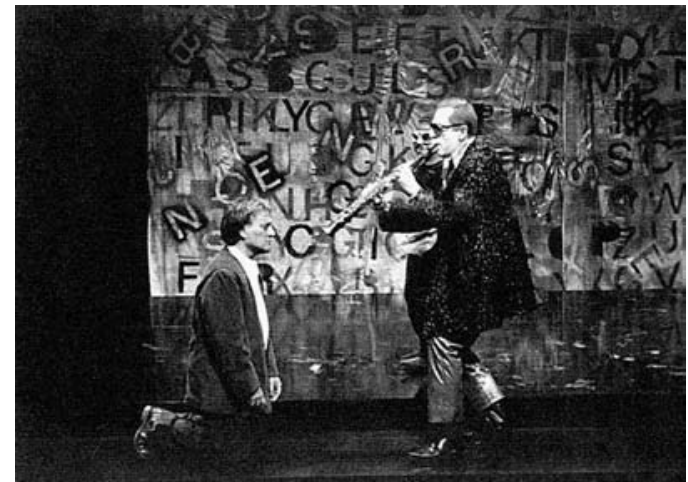

Olavrador da boémia de Johannes von Saaz, enc. Jean-Pierre Sarrazac CCE / CENDREV, 1997 (Fernando Mora Ramos).

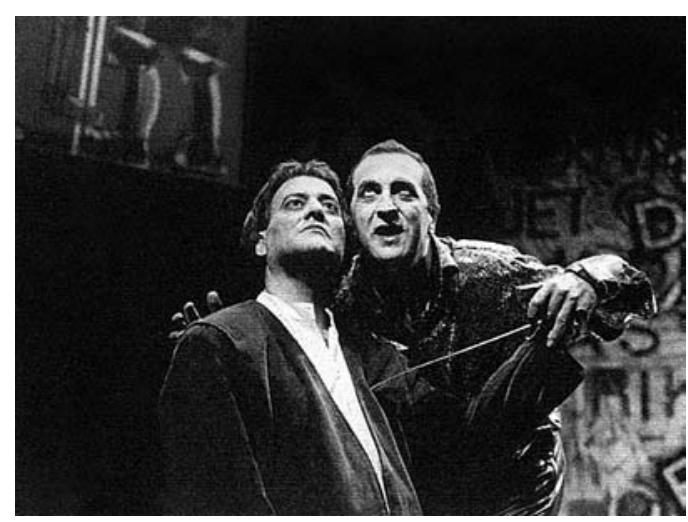

O lavrador da boémia, de Johannes von Saaz, enc. Jean-Pierre Sarrazac CCE / CENDREV, 1997 (Fernando Mora Ramos e Gil Salgueiro Nave). subtis, a sublinhar algumas inovações teatrais bem sucedidas, a combater a banalidade e o mau gosto. Numa perspectiva temporal mais alargada, toda a comunidade dos criticos de teatro acaba por exercer esta influência sobre as ideias teatrais do seu tempo. Promovemos aquilo que a maioria de nós aprecia, criamos personalidades "importantes" do mundo do teatro e destruímos candidatos mais fracos, de que não gostamos. E fazemo-lo porque a comunidade de espectadores guarda na memória o "juizo profissional" e os festivais assentam na discussão pública dos espectáculos, do mesmo modo que a carreira das pessoas de teatro é ou não baseada na reacção dos críticos. A nossa mensagem acaba por exercer algum tipo de influência sobre o gosto artístico do público em certos períodos. E, por isso, a crítica de teatro acaba por exercer uma influência considerável no interior da mentalidade teatral e dos processos teatrais do seu tempo. Esta é a grande responsabilidade que a nossa actividade profissional tem. Esta é a razão pela qual a nossa fraqueza geral comum importa verdadeiramente. E isto é parte de uma outra questão mais vasta: será que verdadeiramente "criamos" uma opinião pública, será que a tornamos mais sofisticada do que antes do nosso envolvimento? Ou será que nos limitamos a expressar a opinião pública da média dos espectadores mais bem informados?

Anunciamos a nossa atitude face a um espectáculo que é sempre baseada num sistema de valores. Fazemolo de um modo que pressupõe que todos nós partilhamos um idêntico sistema de valores, reconhecido de forma generalizada pelos críticos, pelos encenadores e pelos nossos leitores. É algo que surge implícito. Mas os nossos valores são tão diferentes! Quando assistimos a um espectáculo e quando explicamos a nossa atitude face a ele, estamos, de facto, também a anunciar os nossos valores e critérios, ainda que de um modo latente. Quando um crítico disse que aquele espectáculo "dava corpo a 
todo o entusiasmo de um mistério medieval tardio" ou que existia "um rigor em toda a estética em funcionamento, uma agudeza, um brilho", e outro crítico se mostrava seguro de que "o argumento nunca consegue manifestarse com a mesma intensidade dramática" ou que "a ênfase no estilo em detrimento da substância torna-se repetitiva e a mente começa a vaguear", estas conclusões que se contradizem são baseadas em diferentes experiências e formações da ideologia do crítico, embora muitas vezes não possamos senão imaginar que ideologia será. Muitas vezes é importante compreender não só conclusões do autor do artigo, mas também as razões, os pontos de partida, os critérios para o juizo. Temos de discutir as nossas diferenças metodológicas. E, já agora, a AICT é o melhor espaço para o fazermos.

A compreensão sistemática da arte aproxima o crítico do encenador experimentado, cujo trabalho é objecto de análise. Acontece frequentemente avaliarmos métodos teatrais, alguns dos quais assaz específicos, conhecendo unicamente alguns principios gerais emitidos pelo gabinete de imprensa, ou a partir de entrevistas, ou da Internet. Conseguiremos realmente estabelecer juizos de valor e enviar conselhos a criadores teatrais para lá das impressões imediatas dos espectadores? Conseguiremos manter o nivel profissional da discussão em torno da metodologia do encenador ou do actor? Estaremos nós metodologicamente equipados para dialogar com os criadores teatrais? Teremos nós condições para nos envolvermos num diálogo entre parceiros profissionais iguais? Ou nunca passará da conversa de um jornalista com um fazedor de notícias?

A vida teatral contemporânea, bem como a vida dos festivais de teatro, coloca sob os nossos olhos observadores e críticos inúmeras linguagens teatrais. Por vezes, a filosofia e as técnicas desse teatro inovador são completamente inéditas para nós, sobretudo quando as vemos pela primeira vez - Tadashi Suzuki, Christian Lupa, Luc Percival, Andrey Zholdak... Como é que avaliamos um sistema teatral que não conheciamos antes? Provavelmente do mesmo modo por que ele foi criado. Isto é, procurando as suas raizes não num passado próximo, nem na nossa própria experiência, mas nas possibilidades gerais que a forma teatral oferece. E na mentalidade, que pode ter sido expressa de forma tão original. Acredito que o nivel mais elevado de crítica teatral é ser capaz de descrever a forma teatral que parece ser completamente nova, nunca vista, e colocá-la no quadro cultural, explicando as suas peculiaridades comunicativas, identificando os seus antepassados indirectos, etc.
Muitos críticos têm uma espécie de cave secreta onde guardam não só o conhecimento dos modelos teatrais recentes, mas toda a gama de formas teatrais possiveis através da história. É então possivel verdadeiramente descobrir personalidades como Anne Bogart, Christian Lupa, Luc Percival, Andrey Zholdak e outros instigadores do debate teatral, porque compreendemos os seus motivos através de uma pluralidade de modelos e linguagens teatrais - porque os mistérios medievais, a commedia dell'arte e o teatro romântico e muitos outros métodos do teatro ocidental e oriental se revelam decisivos nos caminhos trilhados pela criação contemporânea, mesmo quando não se trata de uma influência reconhecivel, mas simplesmente o tipo de mentalidade ocasionalmente recuperada por uma nova forma teatral. Claro que o podemos fazer sem o recurso a uma terminologia teórica. A nossa preparação profissional deve ficar atrás da cortina. Mas até mesmo breves conclusões, como o sentimento de algo ser estranhamente atraente ou de ser simplesmente algo falso e pretensioso, mesmo este tipo de avaliações exige um estudo metodológico exaustivo que não precisa de ser partilhado com os nossos leitores.

Escrever a critica breve do espectáculo da noite anterior, do ponto de vista profissional, significa escrever uma outra página da história do teatro contemporâneo, colocar uma coisa simples no contexto complexo escondido dos espectadores habituais. Há aspectos da crítica de teatro que podem não ser facilmente acusados de ser simplesmente fantasmas de impressões pessoais ocasionais, como a natureza de certos métodos teatrais, os princípios básicos de composição e do estilo de produção, recursos sistemáticos usados pelo encenador, características específicas das técnicas de representação... Muitos dos nossos colegas, em diversos paises, quando escrevem sobre a estreia da noite anterior, reportam-se a parâmetros estéticos teatrais básicos, mas fazem-no com a mesma imersão como se estivessem a estudar um acontecimento histórico remoto. São os "historiógrafos" do presente.

Talvez estejamos a aproximar-nos do "fim da crítica de teatro convencional". Nós estudamos teatro e fazemolo todas as noites, não numa biblioteca com os velhos manuscritos, mas em salas contemporâneas, cobrindo os mais recentes acontecimentos artísticos que ainda não gozam de reputação.

E é com orgulho que the chamamos critica de teatro! 